Recepción: 18 de febrero de 2021

Aprobación: 31 de mayo de 2021

\title{
FORTALECIMIENTO DE LA ESCUCHA ACTIVA A TRAVÉS DEL AULA INVERTIDA EN UNA INSTITUCIÓN DE EDUCACIÓN BÁSICA DE LA CIUDAD DE BARRANQUILLA, COLOMBIA
}

STRENGTHENING OF ACTIVE LISTENING THROUGH THE FLIPPED CLASSROOM IN A BASIC EDUCATION INSTITUTION IN THE CITY OF BARRANQUILLA, COLOMBIA

FORTALECIMENTO DA ESCUTA ATIVA NA SALA DE AULA INVERTIDA EM UMA INSTITUIÇÃO DE ENSINO FUNDAMENTAL DA CIDADE DE BARRANQUILLA, COLOMBIA

\section{Erica Paola Tejedor Fuentes ${ }^{1}$}

¿Cómo citar este artículo?:

Tejedor Fuentes, E.P. (2021). Fortalecimiento de la escucha activa a través del aula invertida en una institución de educación básica de la ciudad de Barranquilla. Cultura Científica, 19, pp. 105 - 126.

https://doi.org/10.38017/1657463X.708

1 Licenciada en Español y Literatura de la Universidad del Atlántico. eptejedor5@misena.edu.co 


\section{RESUMEN}

En este artículo se quiere demostrar que el aula invertida puede ser utilizada como una herramienta para favorecer el fortalecimiento de la escucha activa. Este trabajo parte de una investigación aplicada que se efectuó en una institución educativa de Barranquilla. La muestra fue de diez estudiantes, donde tres de ellos presentan necesidades educativas especiales (NEE). Se aplicó una metodología desde el paradigma sociocrítico, la investigación cualitativa y el enfoque investigación-acción. A su vez, se hizo necesario el despliegue de cinco fases: la observación, el diagnóstico, la planeación, la ejecución y la evaluación. Se obtuvo como resultados, luego de aplicar el último taller de la propuesta pedagógica diseñada, que nueve de los escolares escucha las ideas de los demás y comparte las propias para realizar trabajos de forma colaborativa; ocho de ellos escucha y responde a las ideas del otro sin utilizar un lenguaje o gestos que lo desmerite o ridiculice; nueve utilizan de forma adecuada el lenguaje no verbal como mirar a las personas que hacen parte del auditorio, mantienen una postura correcta al hablar y escuchar, el tono de voz adecuado para ser escuchado y gestos que indiquen que está escuchando activamente, y solo ocho escucha y responde a las preguntas realizadas de forma puntual y sin desviaciones. Así, se concluye que los estudiantes avanzaron significativamente a lo largo del desarrollo de la propuesta. Se demostró que el aula invertida es una gran herramienta para fortalecer la escucha activa, y conlleva a la adquisición de habilidades como el trabajo en equipo.

Palabras clave: Aula invertida; didáctica; escucha activa; sociedad; trabajo en equipo.

\section{ABSTRACT}

This article wants to show that the flipped classroom can be used as a tool to promote the strengthening of active listening. This work is part of an applied research that was carried out in an educational institution in Barranquilla. The sample consisted of ten students, where three of them present special educational needs (SEN). A methodology was applied from the socio-critical paradigm, qualitative research and the research - action approach. In turn, the deployment of five phases was necessary: observation, diagnosis, planning, execution and evaluation. The results were obtained, after applying the last workshop of the pedagogical proposal designed, that nine of the students listen to the ideas of others and share their own to carry out work collaboratively; eight of them listen and respond to the ideas of the other without using language or gestures that demean or ridicule him; Nine use non-verbal language appropriately, such as looking at people who are part of the audience, maintaining a correct posture when speaking and listening, the appropriate tone 
of voice to be heard and gestures that indicate that they are actively listening and; only eight, listen and answer the questions asked promptly and without deviations. Thus, it is concluded that the students made significant progress throughout the development of the proposal. It was shown that the flipped classroom is a great tool to strengthen active listening, and leads to the acquisition of skills such as teamwork.

Keywords: flipped classroom; didactics; active listening; society; teamwork.

\section{RESUMO}

Este artigo quer mostrar que a sala de aula invertida pode ser usada como uma ferramenta para promover o fortalecimento da escuta ativa. Este trabalho faz parte de uma pesquisa aplicada realizada em uma instituição de ensino de Barranquilla. A amostra foi composta por dez alunos, sendo que três deles apresentam necessidades educacionais especiais (NEE). Foi aplicada uma metodologia a partir do paradigma sociocrítico, da pesquisa qualitativa e da abordagem pesquisa - ação. Por sua vez, foi necessária a implantação de cinco fases: observação, diagnóstico, planejamento, execução e avaliação. Os resultados foram obtidos, após a aplicação da última oficina da proposta pedagógica elaborada, que nove dos alunos ouvem as ideias de outros e compartilham as suas próprias para realizar o trabalho de forma colaborativa; oito deles ouvem e respondem às ideias do outro sem usar linguagem ou gestos que o rebaixem ou ridicularizem; Nove usam a linguagem não verbal de forma adequada, como olhar para as pessoas que fazem parte da plateia, manter postura correta ao falar e ouvir, tom de voz adequado para ser ouvido e gestos que indiquem que estão ouvindo ativamente e; apenas oito, ouçam e respondam às perguntas feitas com prontidão $\mathrm{e}$ sem desvios. Assim, conclui-se que os alunos obtiveram avanços significativos ao longo do desenvolvimento da proposta. Foi demonstrado que a sala de aula invertida é uma ótima ferramenta para fortalecer a escuta ativa, e leva à aquisição de habilidades como o trabalho em equipe.

Palavras chave: sala de aula invertida; didática; escuta activa; sociedade; trabalho em equipe. 
“La comunicación humana tiene dos facetas: hablar y escuchar. Generalmente se piensa que es más importante el hablar, ya que éste parece ser el lado activo de la comunicación, mientras que, al escuchar, se le suele considerar como pasivo"

\section{INTRODUCCIÓN}

Lomas (2002) enfatiza en que la habilidad de escuchar es importante para la adquisición y el desarrollo de los conocimientos. Teniendo en cuenta la usabilidad de las diferentes tecnologías de la información y de la comunicación (TIC), se piensa que incursionarlas en las aulas de clases pudiera ser un aliciente que ha de marcar un hito entre el antes y el ahora con respecto a la enseñanza-aprendizaje. Por tanto, este artículo presenta los resultados de un estudio realizado en una institución de educación básica de la ciudad de Barranquilla, en el que se marcó como objetivo fortalecer la escucha activa desde la escuela mediante el uso del aula invertida. Escuchar activamente es considerado como un proceso complejo que se ve relegado desde el currículo debido a que resulta un tanto difícil enseñar lo que no se ha aprehendido con idoneidad. A partir de esta metodología que ofrece grandes beneficios como el aprender colaborativamente, se considera que los estudiantes ganarán herramientas que les permitirá desenvolverse asertivamente en lo académico, lo laboral y en lo personal.

Autores como Echeverría (1994) apuntalan que la escucha es una competencia muy importante para la vida y el aprendizaje de los seres humanos, señalada como primordial para la construcción de relaciones personales. Como seres sociales, necesitan comunicarse con los que están a su alrededor. A raíz de esta concepción, se promulga el hecho de que el ser humano requie- re de la escucha activa para definir diferentes factores situacionales de su entorno. Así, cuando se entabla una conversación se tienen en cuenta algunos aspectos como la forma de hablar, la manera correcta para expresar las ideas o el tono de voz agradable y no se resalta el lado importante de la conversación: el saber escuchar. "La comunicación humana tiene dos facetas: hablar y escuchar. Generalmente se piensa que es más importante el hablar, ya que éste parece ser el lado activo de la comunicación, mientras que, al escuchar, se le suele considerar como pasivo" (Echeverría, 2002, p. 81). Cuando se escucha activamente es posible comprender, interpretar y responder de la mejor manera a lo que se ha comunicado; "el escuchar es el factor fundamental del lenguaje. Se habla para ser escuchado. El hablar efectivo sólo se logra cuando es seguido de un escuchar efectivo. El escuchar valida el hablar" (Echeverría, 2002, p.82).

El ser humano al iniciar el ciclo de vida empieza a comunicar a través del lenguaje no verbal, más adelante, de manera oral. Luego crece y le enseñan a escribir y a leer, pero nadie le enseña a escuchar. A partir de esta nace la inquietud por ahondar sobre el tema puesto que la mayoría de los estudiantes van a las instituciones educativas con la habilidad de oír y no de escuchar, siendo la primera diferente a la segunda. Echeverría (2006a) afirma que "los problemas de escucha deben ser recíprocos. Quien no se siente escuchado, normalmente tampoco sabe escuchar a los demás” (p. 74). 
El escuchar puede definirse como el proceso por el cual el lenguaje hablado es convertido en significado en la mente (Beuchat, 1989). En consecuencia, se entiende como un proceso que involucra la cultura, el contexto y la forma de pensar de cada individuo, lo cual hace referencia a la capacidad que se tiene para analizar e interpretar aquello que se escucha convirtiéndolo en significación con el fin de darle sentido y comprender el mensaje. En la escuela, es notoria la falta de escucha activa por parte de la mayoría de los estudiantes. "El oyente distraído escucha por momentos porque encuentra mucha dificultad para sostener la atención y se dedica a pasar el tiempo" (Álvarez, 2001). Lo realmente importante es que los educandos aprendan a escuchar de manera activa, para comprender e interpretar lo que les están diciendo, ya que, en palabras de Echeverría (2006b) "la interpretación es el corazón de la escucha” (p. 79). Lo que ratifica lo predominante de desarrollar en el estudiantado este tipo de habilidades, pues una es causa de la otra.

Al realizarse una buena comunicación, la persona que escucha puede interpretar y dar su mejor opinión respecto al tema, por esta razón se pretende afianzar la escucha activa en los estudiantes, para que estos puedan realizar una conversación en donde expresen sus ideas con facilidad y coherencia, tal como lo señala Elizondo (1999):

En la comunicación asertiva, la habilidad de escuchar es básica para el éxito del proceso comunicativo, y para el desarrollo armonioso de las relaciones interpersonales. Dentro del salón de clases, permitirá determinar aspectos como las dudas concretas, las inquietudes, los elementos que generan discusión, los temas que causan conflicto y las posibles formas de solución al mismo, etc. fuera del salón de clases la actividad de asesoría e incluso de un tutoreo de calidad (p. 103).

La escucha activa es la más completa de todas, porque el oyente debe brindar un esfuerzo tanto físico como mental para lograr comprender e interpretar de forma correcta lo que se le está diciendo, a través de gestos, del tono de la voz y retroalimentando lo que ha comprendido de lo dicho. "La escucha activa consiste en una forma de comunicación que demuestra al hablante que el oyente le ha entendido" (García, 2009). Es preciso distinguir que la escucha activa no sólo es prestar atención, también es mostrar con el cuerpo que sí se está comprendiendo lo que se va diciendo, por ejemplo, con una sonrisa, una mirada o un parpadeo. Dando a entender que factores como los no verbales y los paraverbales, en los que se demuestre empatía por el otro, juegan un papel imperativo.

Además, requiere de la empleabilidad de los recursos personales para que el interlocutor sienta que está siendo atendido y comprendido, haciéndole consciente de que lo que intenta transmitir a su oyente es valorado por este (Fernández, 2013). Todo ser humano cuando habla espera ser escuchado a tal punto de sentirse cómodo, pues en

\author{
"La escucha \\ activa consiste \\ en una forma de \\ comunicación que \\ demuestra \\ al hablante que \\ el oyente le ha \\ entendido"
}




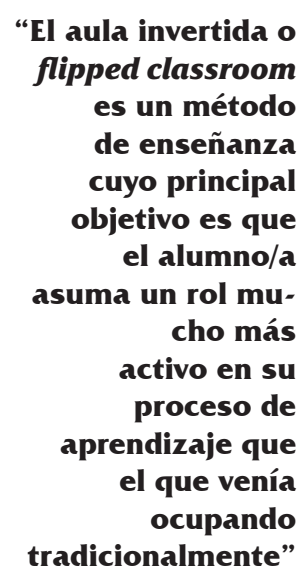

ese momento intervienen factores no solo cognitivos sino emocionales. La escucha activa demanda que la persona que cumple el rol de receptor se introduzca en la mente de quien le habla (emisor) e interprete el mensaje desde su punto de vista. Centra toda la atención en captar y comprender el comunicado, pensamientos y emociones de su interlocutor (Ortiz, 2007). Muchas veces los receptores tienden a anticiparse a responder sin haber por lo menos atendido a lo que el otro intenta darle a conocer, razón por la que es de gran vitalidad el fortalecimiento de la escucha activa.

En consecuencia, se ha propuesto el aula invertida como el vehículo para enfrentar la problemática hallada, gracias a que es un modelo pedagógico pertinente para que el estudiante sea el centro del proceso enseñanza-aprendizaje. "El aula invertida o flipped classroom es un método de enseñanza cuyo principal objetivo es que el alumno/a asuma un rol mucho más activo en su proceso de aprendizaje que el que venía ocupando tradicionalmente" (Berenguer, 2016, p. 1466). En él, se han de trabajar aquellos procesos cognitivos complejos como lo son la memoria, la atención, la comprensión y el lenguaje. A su vez, se basa en las teorías del constructivismo y el aprendizaje colaborativo de Piaget y de la zona de desarrollo próximo propuesta por Vygotsky (Falcones y Yoza, 2018, p. 97).

El aula invertida fue creada por los profesores Jonathan Bergmann y Aaron Sams (2007), con el fin de ayudar a los estudiantes que no po- dían asistir a clases, por lo que se subían videos en Internet relacionados con las temáticas. De esta forma el estudiante desarrollaba su aprendizaje fuera del aula de clases, logrando un buen dominio del tema para socializar y debatir con sus compañeros, aportando sus conocimientos e ideas, logrando un aprendizaje colaborativo, debido a que las clases participativas requieren de atención y escucha para una buena compresión.

Los estudiantes, antes de la clase, tienen que desarrollar los contenidos. Luego, en ella se fomenta la comprensión del contenido (sintetizar, analizar, resolver problemas) a través de un aprendizaje (Walvoord y Johnson, 1998). Por medio del aula invertida el estudiante tendrá un acercamiento al contenido que se desarrollará en la próxima clase, dentro del aula tendrá la oportunidad de profundizar para reflexionar, juzgar, y comprender críticamente, mediante la retroalimentación dada por el docente se resolverán las dudas. De esta forma se espera que el estudiante desarrolle las habilidades del pensamiento y sea el protagonista de la clase, el docente tendrá que propiciar ambientes de trabajo didácticos e interactivos y el estudiante asumirá la responsabilidad sobre su propio aprendizaje.

Haciendo un consenso, es posible dar cuenta de que el alumnado está inmerso en el mundo digital, tiene acceso a diversos tipos de informaciones, estos educandos son denominados "residentes", ya que recurren a las diferentes plataformas virtuales diariamente para con- 
sultar tareas, indagar, etc., logrando recibir la información en segundos. Asimismo, se caracterizan por compartir ideas en línea, tienen perfiles en redes sociales, mantienen una identidad digital, y son totalmente activos en el mundo virtual (White y Le Cornu, 2011).

Teniendo en cuenta la generación actual, Prensky (2001) invita a los educadores a implementar nuevas formas de enseñar. "Educadores y profesores Inmigrantes Digitales realmente desean contactar, comunicarse e interactuar con los estudiantes Nativos Digitales, que son todos los que constituyen nuestra actualidad, tendrán que someterse al cambio". Prensky (2001) afirma que es notable que en el presente los jóvenes y niños desde sus primeros años tienen acceso a herramientas tecnológicas, lo cual genera gran habilidad en su uso, ya que hacen parte de su rutina diaria. Es por ello que el docente debe utilizar como parte del proceso enseñanza-aprendizaje la implementación de estos dispositivos para motivar al estudiante a indagar y a explorar correctamente información y contenidos en la web, ya que los métodos tradicionales de enseñanza generan desinterés por aprender.

A partir de las teorías expuestas anteriormente, es notable lo fundamental de fortalecer la habilidad de la escucha activa, pues es parte vital para el aprendizaje y la comunicación. De igual manera, es benéfico el uso del aula invertida como modelo pedagógico gracias a que facilita obtención de información y de contenidos en la web para propiciar ambientes participativos en el aula de clase.

A raíz de lo dicho, esta metodología da pie al aprendizaje por experiencia. Por ello, partiendo de la aseveración de Dewey $(1899$, p. 25), "cuando el niño llega al aula ya es intensamente activo y el cometido de la educación consiste en tomar a su cargo esta actividad y orientarla". Es pertinente reconocer lo fundamental de la labor del docente para el desarrollo del proceso enseñanza-aprendizaje; es decir, el docente debe ser un guía que ayude a promover y fortalecer al estudiante como un ser activo de manera que sea capaz de construir su propio conocimiento y desarrolle un pensamiento crítico.

De igual modo, Dewey (1899) expone que cuando el niño empieza su escolaridad lleva en sí "cuatro impulsos innatos, el de comunicar, el de construir, el de indagar y el expresarse de forma más precisa" (p. 30). Con lo anterior se corrobora el potencial que tiene el estudiante para desarrollarse de manera activa en el aula de clases logrando aprender y conocer mediante sus capacidades innatas.

Desde la perspectiva de Vygotsky (1978) se entiende que "el aprendizaje despierta una variedad de procesos de desarrollo que son capaces de operar sólo cuando el niño interactúa con otras personas y en colaboración con sus compañeros". Es decir, socializar las ideas libremente con los demás en un ambiente de cooperación facili- 
ta un mejor aprendizaje y permite que el estudiante conozca diferentes perspectivas de un tema para así crear nuevos conocimientos. A partir de esto, se concibe el aprendizaje de forma colaborativa. "El aprendizaje cooperativo es el uso educativo de pequeños grupos que permiten a los estudiantes trabajar juntos para mejorar su propio aprendizaje y el de los demás" (Johnson y Johnson, 1991). Esto da cuenta de que es necesario que los estudiantes intercambien ideas e información para alcanzar un aprendizaje significativo.

En resumen, el fomentar desde la escuela espacios y situaciones en las que el alumnado tenga la oportunidad de manifestar su pensamiento ante una temática específica a través del debate, hará que este se forme para la vida, debido a que tendrá las capacidades y la habilidad de desenvolverse en distintos contextos partiendo de la criticidad que haya adquirido.

\section{METOdOLOGÍA}

De acuerdo al alcance de este proyecto de investigación realizado en una institución de educación básica de la ciudad de Barranquilla, se vio pertinente abordarlo desde el paradigma socio-crítico, del tipo de investigación cualitativa y del enfoque participación-acción. Las técnicas e instrumentos de recolección de datos utilizados fueron el diario de campo, en el que se consignaron treinta observaciones dadas durante las clases; la prueba diagnóstica aplicada a los educandos y los talleres realizados a lo largo del se- gundo trimestre del año 2018, con el propósito de registrar de forma narrativa y descriptiva las observaciones y las actividades que el grupo investigador planeó en todo el transcurrir de la investigación. Una encuesta conformada por diez preguntas, siendo una de ellas: ¿consideras importante escuchar y ser escuchado? Una entrevista integrada por siete preguntas dirigidas a la docente de español. Y una rejilla de evaluación adaptada a partir de la estructura diseñada por González y Castro (2014) en su "Libro del gran artista" para la que tuvieron en cuenta los tres pilares de la educación: saber saber o saber conocer, saber hacer y saber ser. Por tanto, esta ha sido segmentada en tres categorías las cuales llevan por nombre dichos pilares. En ella, se rotuló a cada miembro del curso con el literal "E" tomado de la inicial de la palabra estudiante acompañado del número que ocupaba en el listado que se tenía de sus nombres por orden alfabético (ejemplo: E1). Mientras que los ítems de evaluación que se establecieron fueron de manera congénita bajo las teorías que sirvieron de pie para la creación de una propuesta pedagógica.

Teniendo en cuenta lo anterior, el trabajo de investigación partió de cinco etapas en las que se evidencian la aplicación de tales técnicas e instrumentos. La observación, en donde se registró de forma visual todo cuanto ocurrió en las situaciones reales, entre ellas, la conducta y las características del grupo objeto de estudio. El diagnóstico, se grabó a los estudiantes (con aproba- 
ción previa) mientras realizaban una exposición acerca de un tema asignado por la docente de lengua castellana, luego se hizo una encuesta a los diez dicentes quienes hacían parte del grado quinto de primaria y, por último, se realizó una entrevista a la docente de la asignatura mencionada en la que habló sobre el comportamiento de los estudiantes dentro del aula, de su conocimiento sobre escucha activa y de las estrategias implementadas por ella para lograr que los mismos puedan escuchar. La planeación, se elaboró una propuesta pedagógica basada en la metodología del aula invertida teniendo en cuenta la pedagogía por proyectos, flippeando, mi oído voy afinando, la cual se compone de once talleres diferentes en los que se abordan temáticas correspondientes a la materia de español propias del grado al que pertenecen los escolares. Esto con el fin de proporcionar una guía práctica para que los docentes tengan una orientación clara de cómo abordar esta metodología al interior del salón de clases.

Cabe precisar que el aula invertida o Flipped classroom es un enfoque que advierte una secuencia lógica, que necesita ser aprehendida por los educadores correctamente para lograr los objetivos y metas deseadas. Esta metodología cumple con tres momentos:

\subsection{Antes (Exploración)}

Programación: el docente debe elegir el tema a trabajar, definir los objetivos y logros a alcanzar.
Preparación de materiales: deben ser escogidos de acuerdo con el tema y a las necesidades de los estudiantes. Estos son contenidos digitales que pueden ser creados y diseñados por el docente o tomados de la web. Van a acompañados de un test $o$ una actividad a realizar en casa con el fin de comprobar que los estudiantes revisaron los materiales y realizaron la debida exploración.

Visualización y lectura de los materiales en casa: el docente debe enviar los materiales al educando a través del medio que haya convenido (redes sociales, plataforma educativa institucional, blog, correo electrónico, etcétera) para que los estudiantes lo revisen las veces que les sea necesario para luego desarrollar el test o la actividad adjunta. El estudiante debe anotar las inquietudes para ser compartidas al docente en la clase.

Diseño de las sesiones de clase: el educador debe preparar su clase con base en las necesidades de cada uno de sus alumnos y de las posibles inquietudes que les surjan. Elegirá y diseñará actividades tanto grupales como individuales que les exijan a los estudiantes un aprendizaje activo.

Resolución de dudas: el profesor debe tener en cuenta actividades en las que logre resolver las dudas de los estudiantes partiendo de la construcción de saberes colaborativos. Es decir, todos deben participar para que se despejen las inquietudes y se aprehenda el contenido a trabajar en clase.

\author{
El aula invertida o \\ Flipped classroom \\ es un enfoque \\ que advierte una \\ secuencia lógica, \\ que necesita ser \\ aprehendida por \\ los educadores \\ correctamente \\ para lograr los \\ objetivos y metas \\ deseadas.
}




\subsection{Durante (Confrontación)}

Actividades de consolidación: los conceptos y conocimientos adquiridos deben ser consolidados por medio de actividades (estas pueden ser dentro o fuera del aula) que le permitan al estudiante desarrollar habilidades y competencias en pro de alcanzar los logros y objetivos propuesto por el docente.

\subsection{Después (Transferencia)}

Revisión y repaso: el docente debe propiciar espacios en los que anime a los estudiantes a dar sus opiniones sobre lo aprendido utilizando preguntas abiertas en las que pueda conocer si realmente han aprehendido el tema trabajado durante la clase. En estos espacios también se han de despejar dudas.

Evaluación y autoevaluación: el docente evaluará el trabajo de sus estudiantes utilizando rúbricas en las que se sienten los objetivos y logros a alcanzar planteados al inicio de la clase. Para los estudiantes también puede proponer una autoevaluación (escrita u oral), con esto ha de incentivar en ellos la crítica y la reflexión ayudándoles a mejorar.

Dado lo anterior, a cada taller se le asignó un título referido al tema a tratar. Esta, estuvo sometida a tres fases en las que se escogieron los temas, se diseñaron las actividades y se elaboró la rejilla de evaluación para cada uno de los talleres. También, se hizo necesario crear un blog para subir el material de las actividades de cada taller a traba- jar. La propuesta busca fortalecer la escucha activa en los estudiantes utilizando como vehículo el aula invertida. La ejecución, se aplicaron los talleres en el aula durante la clase de lenguaje. Y, evaluación, se evaluó la prueba diagnóstica y cada taller realizado con la rejilla bosquejada por el grupo investigador. Con base en los datos recogidos, se logró establecer los resultados y las conclusiones.

Para finalizar, se optó por presentar los resultados de los talleres uno, cuatro, ocho y once porque no se consideró pertinente presentarlos todos, además, a partir de los seleccionados, es posible dar cuenta de que sí hubo avances significativos. A su vez, estos permiten realizar una comparación detallada entre el último y los que le anteceden para determinar si realmente el aula invertida puede ser empleada como una herramienta que promueve el fortalecimiento de la escucha activa. Del mismo modo, se efectuó la triangulación de los instrumentos utilizados para la recolección de datos. Pues al hacerlo se ha de articular la información obtenida para luego mostrar los hallazgos que han dado lugar a reflexiones, análisis y conclusiones.

\section{Resultados}

Para este apartado, se dará muestra de la triangulación hecha del análisis de los resultados obtenidos de los talleres uno, cuatro, ocho y once; de la observación a los estudiantes y de la prueba diagnóstica. 
Tabla 1. Triangulación con relación al taller 1

\begin{tabular}{|c|c|c|c|c|c|c|c|c|}
\hline \multirow{3}{*}{ Ũ } & \multirow{3}{*}{ Unidad de análisis } & \multicolumn{7}{|c|}{ Triangulación } \\
\hline & & \multicolumn{2}{|c|}{ Observación } & \multicolumn{2}{|c|}{$\begin{array}{c}\text { Prueba } \\
\text { diagnóstica }\end{array}$} & \multicolumn{2}{|c|}{ Taller \# 1} & \multirow{2}{*}{ Resultados } \\
\hline & & Sí & No & Sí & No & Sí & No & \\
\hline \multirow{4}{*}{ 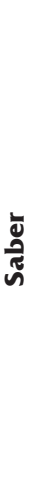 } & $\begin{array}{l}\text { Reconoce la diferencia entre } \\
\text { oír y escuchar. }\end{array}$ & 0 & 10 & 0 & 10 & 0 & 10 & \multirow{10}{*}{$\begin{array}{l}\text { De acuerdo a los re- } \\
\text { sultados de las eva- } \\
\text { luaciones aplicadas } \\
\text { a los estudiantes de } \\
\text { quinto grado y, pese } \\
\text { a la intervención rea- } \\
\text { lizada con la aplica- } \\
\text { ción del primer taller, } \\
\text { en este punto, aún no } \\
\text { saben distinguir entre } \\
\text { oír y escuchar, pero sí } \\
\text { reconocen la impor- } \\
\text { tancia de escuchar a } \\
\text { sus compañeros, aun- } \\
\text { que no lo ponen en } \\
\text { práctica. Además, tie- } \\
\text { nen mayor dificultad } \\
\text { al momento de traba- } \\
\text { jar en equipo puesto } \\
\text { que no escuchan las } \\
\text { opiniones e ideas de } \\
\text { sus compañeros y } \\
\text { están dispuestos a } \\
\text { hacer prevalecer las } \\
\text { propias. }\end{array}$} \\
\hline & $\begin{array}{l}\text { Reconoce la diferencia entre } \\
\text { trabajo en equipo y trabajo } \\
\text { en grupo. }\end{array}$ & 0 & 10 & 0 & 10 & 0 & 10 & \\
\hline & $\begin{array}{l}\text { Reconoce la importancia de } \\
\text { escuchar para aprender. }\end{array}$ & 1 & 9 & 2 & 8 & 3 & 7 & \\
\hline & $\begin{array}{l}\text { Reconoce la importancia de } \\
\text { escuchar a los demás para } \\
\text { poder llegar a un consenso } \\
\text { mientras trabaja de forma } \\
\text { colaborativa. }\end{array}$ & 3 & 7 & 2 & 8 & 4 & 6 & \\
\hline \multirow{4}{*}{ 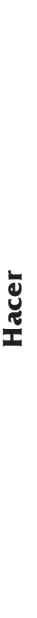 } & $\begin{array}{l}\text { Utiliza su lenguaje verbal y } \\
\text { no verbal para explicar de } \\
\text { forma clara el mensaje que } \\
\text { pretende transmitir. }\end{array}$ & 3 & 7 & 2 & 8 & 0 & 10 & \\
\hline & $\begin{array}{l}\text { Demuestra de forma verbal } \\
\text { que escucha a los demás de } \\
\text { manera activa. }\end{array}$ & 1 & 9 & 1 & 9 & 0 & 10 & \\
\hline & $\begin{array}{l}\text { Responde de forma precisa } \\
\text { y acertada a lo que se le ha } \\
\text { preguntado con relación a la } \\
\text { temática y a lo expuesto por } \\
\text { sus compañeros. }\end{array}$ & 1 & 9 & 2 & 8 & 2 & 8 & \\
\hline & $\begin{array}{l}\text { Escucha, organiza y plasma } \\
\text { sus ideas oralmente de for- } \\
\text { ma fluida y coherente. }\end{array}$ & 3 & 7 & 2 & 8 & 2 & 8 & \\
\hline \multirow{2}{*}{ ڤั } & $\begin{array}{l}\text { Demuestra interés por parti- } \\
\text { cipar de las actividades pro- } \\
\text { puestas. }\end{array}$ & 7 & 3 & 8 & 2 & 9 & 1 & \\
\hline & $\begin{array}{l}\text { Pide la palabra y respeta los } \\
\text { turnos al hablar o expresar } \\
\text { su opinión. }\end{array}$ & 0 & 10 & 0 & 10 & 0 & 10 & \\
\hline
\end{tabular}

Fuente: tomada de la rejilla de evaluación de elaboración propia con base en la estructura propuesta por González y Castro en su “Libro del gran artista” (2014). 
Figura 1. Triangulación con relación al taller 1

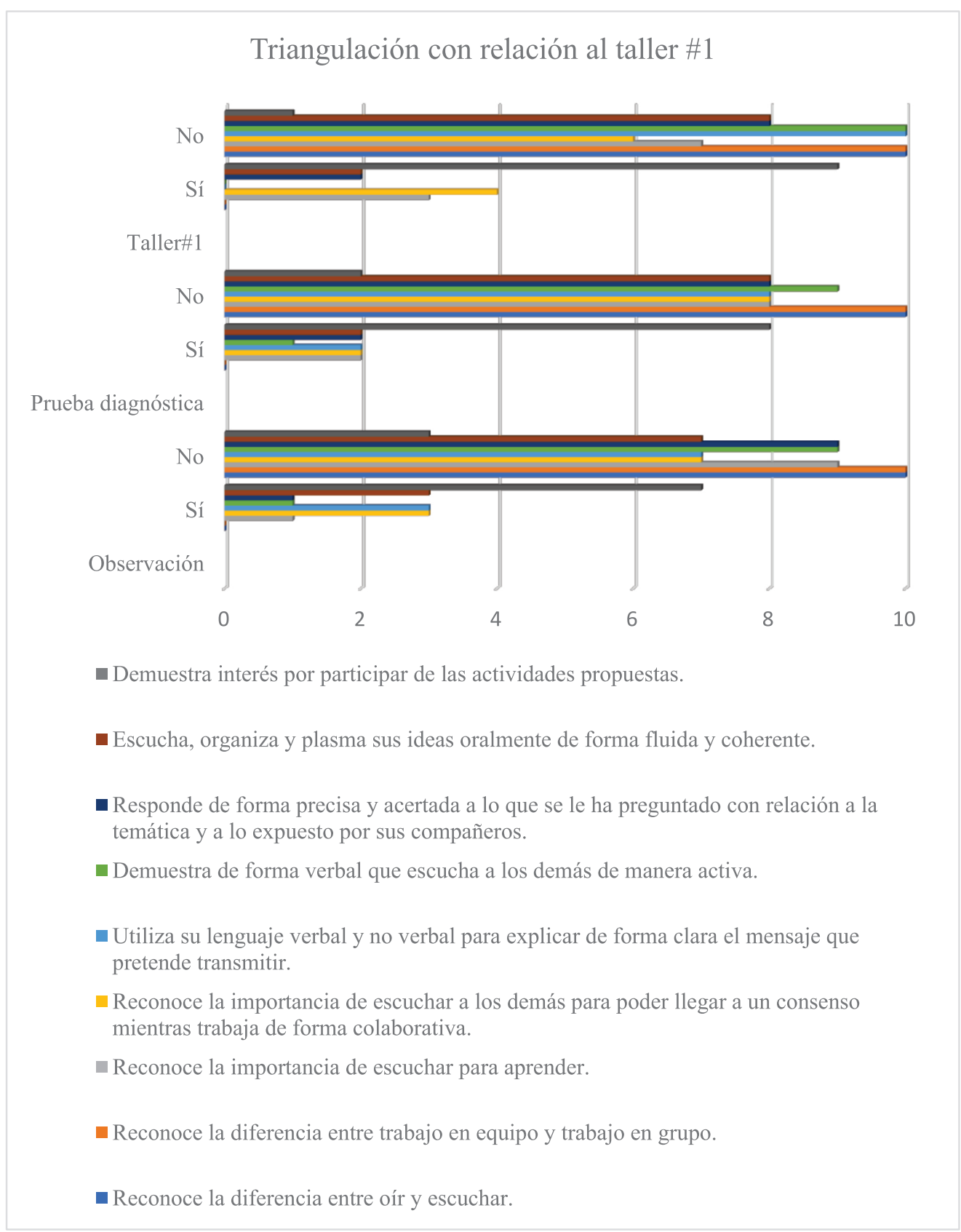

Fuente: elaboración propia.

No. 19 enero - diciembre de 2021 - ISSN 1657-463X - e-ISSN: 2389-9638 
Tabla 2. Triangulación relacionada con el taller 4.

\begin{tabular}{|c|c|c|c|c|c|c|c|c|}
\hline \multirow{3}{*}{ Uै } & \multirow{3}{*}{ Unidad de análisis } & \multicolumn{7}{|c|}{ Triangulación } \\
\hline & & \multicolumn{2}{|c|}{ Observación } & \multicolumn{2}{|c|}{$\begin{array}{c}\text { Prueba } \\
\text { diagnóstica }\end{array}$} & \multicolumn{2}{|c|}{ Taller \#4 } & \multirow{2}{*}{ Resultados } \\
\hline & & Sí & No & Sí & No & Sí & No & \\
\hline \multirow{4}{*}{$\frac{\bar{\Sigma}}{\stackrel{\sim}{\sim}}$} & $\begin{array}{l}\text { Reconoce la importancia de } \\
\text { respetar los turnos al ha- } \\
\text { blar y de no adelantarse a } \\
\text { responder ante lo que se le } \\
\text { dice. }\end{array}$ & 0 & 10 & 0 & 10 & 4 & 6 & \multirow{10}{*}{$\begin{array}{l}\text { Para este momento, } \\
\text { es evidente que si- } \\
\text { guen interrumpiendo } \\
\text { a la persona que tiene } \\
\text { la palabra y no espe- } \\
\text { ran su turno para dar } \\
\text { su opinión respecto } \\
\text { al tema abordado. De } \\
\text { manera individual, los } \\
\text { resultados permiten } \\
\text { identificar que cuatro } \\
\text { de los estudiantes } \\
\text { (E1, E2, E3, y E9) al- } \\
\text { canzaron el 100\% de } \\
\text { la evaluación, mien- } \\
\text { tras que los seis res- } \\
\text { tantes siguen presen- } \\
\text { tando dificultades de } \\
\text { escucha activa, espe- } \\
\text { cíficamente el estu- } \\
\text { diante E4, quien no } \\
\text { logró alcanzar ningún } \\
\text { criterio a satisfacción, } \\
\text { por lo cual es necesa- } \\
\text { rio continuar fortale- } \\
\text { ciendo su escucha ya } \\
\text { que a la vez logrará } \\
\text { mejorar en su rendi- } \\
\text { miento académico. } \\
\text { Es importante resaltar } \\
\text { que este último, pre- } \\
\text { senta una discapaci- } \\
\text { dad auditiva provo- } \\
\text { cada a causa de que } \\
\text { tuvo complicaciones } \\
\text { al nacer. }\end{array}$} \\
\hline & $\begin{array}{l}\text { Reconoce la importancia de } \\
\text { atender para poder escu- } \\
\text { char y de este modo com- } \\
\text { prender y responder ante lo } \\
\text { que se le dice. }\end{array}$ & 2 & 8 & 1 & 9 & 6 & 4 & \\
\hline & $\begin{array}{l}\text { Reconoce la importancia de } \\
\text { escuchar a los demás. }\end{array}$ & 1 & 9 & 2 & 8 & 7 & 3 & \\
\hline & $\begin{array}{l}\text { Reconoce la importancia de } \\
\text { escuchar a los demás para } \\
\text { poder llegar a un consenso } \\
\text { mientras trabaja de forma } \\
\text { colaborativa. }\end{array}$ & 3 & 7 & 2 & 8 & 5 & 5 & \\
\hline \multirow{4}{*}{$\begin{array}{l}\bar{\Xi} \\
\stackrel{U}{I} \\
I\end{array}$} & $\begin{array}{l}\text { Utiliza los elementos de co- } \\
\text { hesión, coherencia y sintaxis } \\
\text { en su discurso. }\end{array}$ & 2 & 8 & 2 & 8 & 6 & 4 & \\
\hline & $\begin{array}{l}\text { Escucha y responde a las } \\
\text { ideas del otro sin utilizar } \\
\text { un lenguaje o gestos que lo } \\
\text { desmerite o ridiculice. }\end{array}$ & 1 & 9 & 1 & 9 & 5 & 5 & \\
\hline & $\begin{array}{l}\text { Escucha y comprende la } \\
\text { temática siendo capaz de } \\
\text { plasmarla de forma escrita, } \\
\text { gráfica o icónica. }\end{array}$ & 1 & 9 & 2 & 8 & 7 & 3 & \\
\hline & $\begin{array}{l}\text { Habla de forma clara y } \\
\text { precisa. }\end{array}$ & 3 & 7 & 2 & 8 & 1 & 9 & \\
\hline \multirow[b]{2}{*}{ 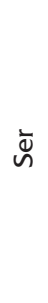 } & $\begin{array}{l}\text { Demuestra interés por parti- } \\
\text { cipar de las actividades pro- } \\
\text { puestas. }\end{array}$ & 7 & 3 & 8 & 2 & 10 & 0 & \\
\hline & $\begin{array}{l}\text { Manifiesta de forma adecua- } \\
\text { da sus desacuerdos, siendo } \\
\text { tolerante con sus compañe- } \\
\text { ros a la hora de trabajar de } \\
\text { forma colaborativa. }\end{array}$ & 0 & 10 & 0 & 10 & 6 & 4 & \\
\hline
\end{tabular}

Fuente: tomado de la rejilla de evaluación de elaboración propia con base en la estructura propuesta por González y Castro en su “Libro del gran artista” (2014). 
Figura 2. Triangulación con relación al taller 4

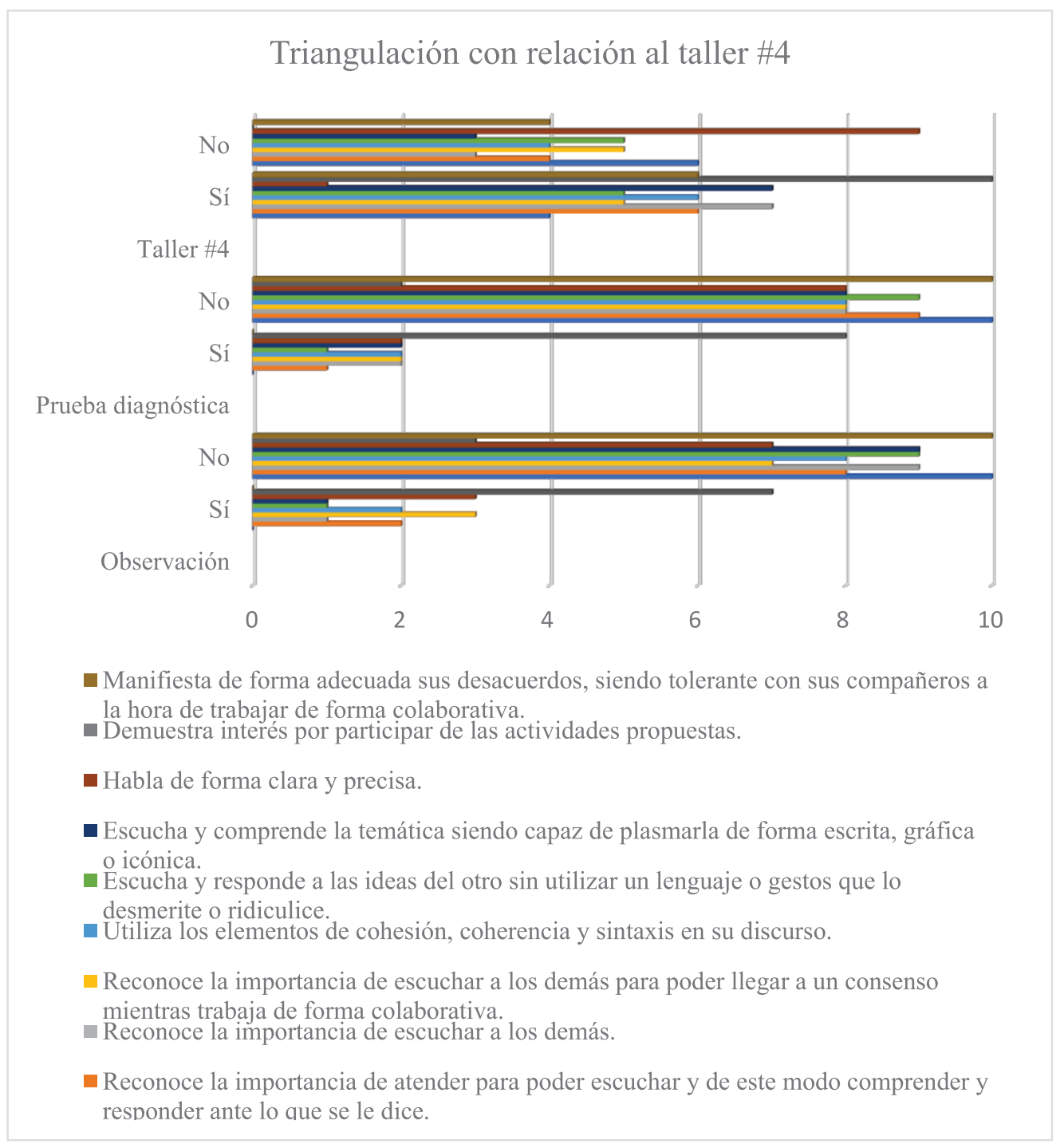

Fuente: elaboración propia. 
Tabla 3. Triangulación relacionada con el taller 8.

\begin{tabular}{|c|c|c|c|c|c|c|c|c|}
\hline \multirow{3}{*}{ Ũ } & \multirow{3}{*}{ Unidad de análisis } & \multicolumn{7}{|c|}{ Triangulación } \\
\hline & & \multicolumn{2}{|c|}{ Observación } & \multicolumn{2}{|c|}{$\begin{array}{c}\text { Prueba } \\
\text { diagnóstica }\end{array}$} & \multicolumn{2}{|c|}{ Taller \#8 } & \multirow{2}{*}{ Resultados } \\
\hline & & Sí & No & Sí & No & Sí & No & \\
\hline \multirow{4}{*}{$\frac{\text { d }}{\text { ज̆ }}$} & $\begin{array}{l}\text { Reconoce la diferencia entre } \\
\text { oír y escuchar. }\end{array}$ & 0 & 10 & 0 & 10 & 10 & 0 & \multirow{10}{*}{$\begin{array}{l}\text { En esta evaluación } \\
\text { es notablemente el } \\
\text { avance que tuvie- } \\
\text { ron los estudiantes, } \\
\text { pues, a nivel general } \\
\text { se han visto compro- } \\
\text { metidos y motivados } \\
\text { a la hora de realizar } \\
\text { las actividades pro- } \\
\text { puestas. De manera } \\
\text { individual, se observa } \\
\text { que ocho de los estu- } \\
\text { diantes alcanzaron un } \\
80 \% \text { de los criterios } \\
\text { de evaluación, y dos } \\
\text { de los estudiantes (E4 } \\
\text { y E8) aún evidencian } \\
\text { algunas falencias de- } \\
\text { bido a que presentan } \\
\text { problemas de habla y } \\
\text { escucha (trastornos), } \\
\text { sin embargo, su me- } \\
\text { joría ha sido conside- } \\
\text { rable en comparación } \\
\text { al primer taller. }\end{array}$} \\
\hline & $\begin{array}{l}\text { Reconoce la importancia de } \\
\text { escuchar a los demás para } \\
\text { poder llegar a un consenso } \\
\text { mientras trabaja de forma } \\
\text { colaborativa. }\end{array}$ & 3 & 7 & 2 & 8 & 9 & 1 & \\
\hline & $\begin{array}{l}\text { Reconoce la importancia de } \\
\text { escuchar a los demás. }\end{array}$ & 3 & 7 & 2 & 8 & 8 & 2 & \\
\hline & $\begin{array}{l}\text { Reconoce la importancia de } \\
\text { respetar los turnos al ha- } \\
\text { blar y de no adelantarse a } \\
\text { responder ante lo que se le } \\
\text { dice. }\end{array}$ & 0 & 10 & 0 & 10 & 10 & 0 & \\
\hline \multirow{4}{*}{ 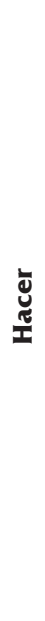 } & $\begin{array}{l}\text { Escucha, organiza y plasma } \\
\text { sus ideas oralmente de for- } \\
\text { ma fluida y coherente. }\end{array}$ & 3 & 7 & 2 & 8 & 9 & 1 & \\
\hline & $\begin{array}{l}\text { Demuestra de forma verbal } \\
\text { que escucha a los demás de } \\
\text { manera activa. }\end{array}$ & 1 & 9 & 1 & 9 & 8 & 2 & \\
\hline & $\begin{array}{l}\text { Responde de forma precisa } \\
\text { y acertada a lo que se le ha } \\
\text { preguntado con relación a la } \\
\text { temática y a lo expuesto por } \\
\text { sus compañeros. }\end{array}$ & 1 & 9 & 2 & 8 & 7 & 3 & \\
\hline & $\begin{array}{l}\text { Escucha las ideas de los de- } \\
\text { más y comparte las propias } \\
\text { para realizar trabajos de for- } \\
\text { ma colaborativa. }\end{array}$ & 3 & 7 & 2 & 8 & 9 & 1 & \\
\hline \multirow{2}{*}{ ฝั } & $\begin{array}{l}\text { Demuestra interés por parti- } \\
\text { cipar de las actividades pro- } \\
\text { puestas. }\end{array}$ & 7 & 3 & 8 & 2 & 10 & 0 & \\
\hline & $\begin{array}{l}\text { Pide la palabra y respeta los } \\
\text { turnos al hablar o expresar } \\
\text { su opinión. }\end{array}$ & 0 & 10 & 0 & 10 & 9 & 1 & \\
\hline
\end{tabular}

Fuente: tomado de la rejilla de evaluación de elaboración propia con base en la estructura de González y Castro en su "Libro del gran artista” (2014). 
Figura 3. Triangulación con relación al taller 8

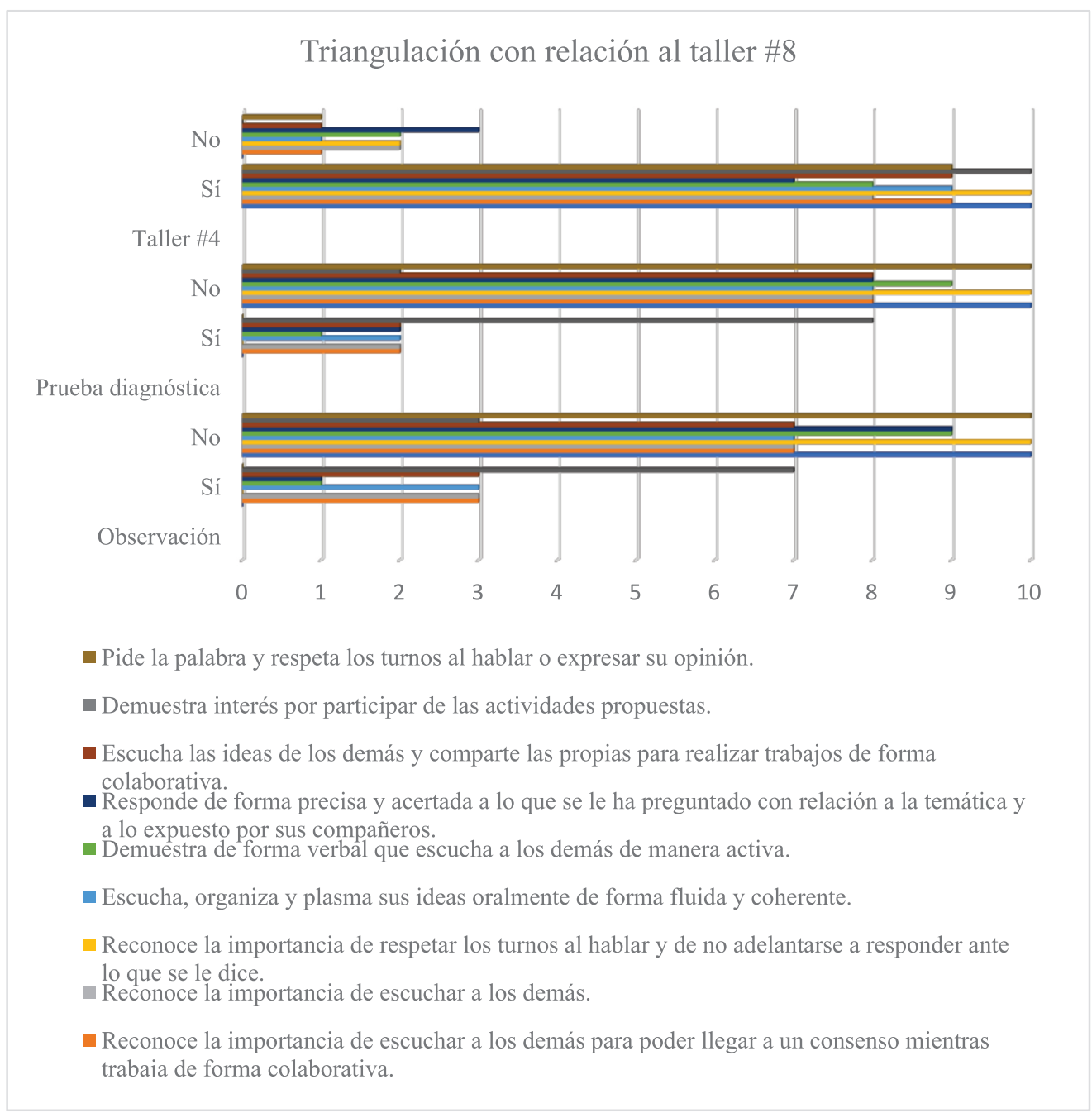

Fuente: elaboración propia.

Tabla 4. Triangulación relacionada con el taller 11

\begin{tabular}{|c|c|c|c|c|c|c|c|c|}
\hline \multirow{3}{*}{ 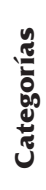 } & \multirow{3}{*}{ Unidad de análisis } & \multicolumn{7}{|c|}{ Triangulación } \\
\hline & & \multicolumn{2}{|c|}{ Observación } & \multicolumn{2}{|c|}{$\begin{array}{c}\text { Prueba } \\
\text { diagnóstica }\end{array}$} & \multicolumn{2}{|c|}{ Taller \# 11} & \multirow{2}{*}{ Resultados } \\
\hline & & Sí & No & Sí & No & Sí & No & \\
\hline \multirow{2}{*}{ ڤัँ } & $\begin{array}{l}\text { Reconoce la importan- } \\
\text { cia de respetar los tur- } \\
\text { nos al hablar y de no } \\
\text { adelantarse a responder } \\
\text { ante lo que se le dice. }\end{array}$ & 0 & 10 & 0 & 10 & 10 & 0 & \multirow{2}{*}{$\begin{array}{l}\text { A través de los resultados } \\
\text { expuestos en la tabla y la } \\
\text { figura } 4 \text { correspondientes } \\
\text { a la triangulación relacio- } \\
\text { nada con el taller once, es } \\
\text { posible dar cuenta de que } \\
\text { el aula invertida aplicada } \\
\text { como metodología en el } \\
\text { grado quinto de una ins- }\end{array}$} \\
\hline & $\begin{array}{l}\text { Reconoce que a través } \\
\text { de la escucha se adquie- } \\
\text { re información. }\end{array}$ & 0 & 10 & 0 & 10 & 10 & 0 & \\
\hline
\end{tabular}


Tabla 4. (Cont.)

\begin{tabular}{|c|c|c|c|c|c|c|c|c|}
\hline \multirow[t]{2}{*}{$\begin{array}{l}\text { d } \\
\frac{\hat{\sigma}}{\tilde{\tau}}\end{array}$} & $\begin{array}{l}\text { Reconoce que un de- } \\
\text { bate es un espacio para } \\
\text { dar su punto de vista } \\
\text { sobre un tema en es- } \\
\text { pecífico basándose en } \\
\text { argumentos. }\end{array}$ & 1 & 9 & 2 & 8 & 9 & 1 & \multirow{8}{*}{ 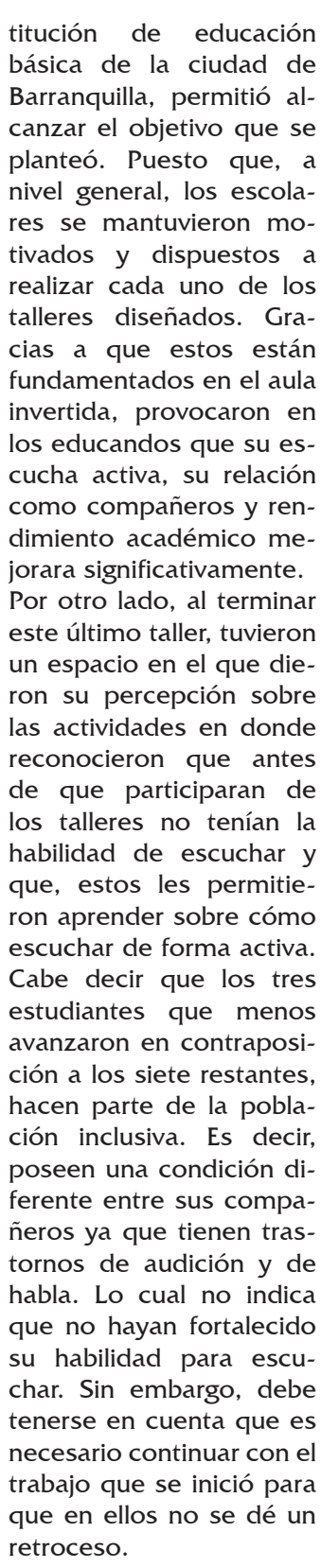 } \\
\hline & $\begin{array}{l}\text { Conoce la finalidad de } \\
\text { un resumen. }\end{array}$ & 3 & 7 & 2 & 8 & 7 & 3 & \\
\hline \multirow{4}{*}{ 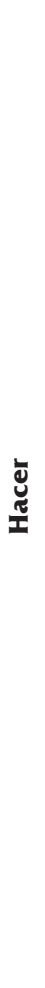 } & $\begin{array}{l}\text { Escucha las ideas de } \\
\text { los demás y comparte } \\
\text { las propias para realizar } \\
\text { trabajos de forma cola- } \\
\text { borativa. }\end{array}$ & 3 & 7 & 2 & 8 & 9 & 1 & \\
\hline & $\begin{array}{l}\text { Escucha y responde a } \\
\text { las ideas del otro sin uti- } \\
\text { lizar un lenguaje o ges- } \\
\text { tos que lo desmerite o } \\
\text { ridiculice. }\end{array}$ & 1 & 9 & 1 & 9 & 8 & 2 & \\
\hline & $\begin{array}{l}\text { Utiliza de forma ade- } \\
\text { cuada el lenguaje no } \\
\text { verbal como mirar a } \\
\text { las personas que ha- } \\
\text { cen parte del auditorio, } \\
\text { mantener una postura } \\
\text { correcta al hablar y es- } \\
\text { cuchar, el tono de voz } \\
\text { adecuado para ser es- } \\
\text { cuchado y gestos que } \\
\text { indiquen que está escu- } \\
\text { chando activamente. }\end{array}$ & 1 & 9 & 2 & 8 & 9 & 1 & \\
\hline & $\begin{array}{l}\text { Escucha y responde a } \\
\text { las preguntas realizadas } \\
\text { de forma puntual y sin } \\
\text { desviaciones. }\end{array}$ & 3 & 7 & 2 & 8 & 8 & 2 & \\
\hline \multirow[b]{2}{*}{ ๗ँ } & $\begin{array}{l}\text { Demuestra interés por } \\
\text { participar de las activi- } \\
\text { dades propuestas. }\end{array}$ & 7 & 3 & 8 & 2 & 10 & 0 & \\
\hline & $\begin{array}{l}\text { Manifiesta de forma } \\
\text { adecuada sus desacuer- } \\
\text { dos, siendo tolerante } \\
\text { con sus compañeros a } \\
\text { la hora de trabajar de } \\
\text { forma colaborativa. }\end{array}$ & 0 & 10 & 0 & 10 & 8 & 2 & \\
\hline
\end{tabular}

Fuente: tomado de la rejilla de evaluación de elaboración propia con base en la estructura propuesta por González y Castro en su “Libro del gran artista” (2014). 
Figura 4. Triangulación con relación al taller 11

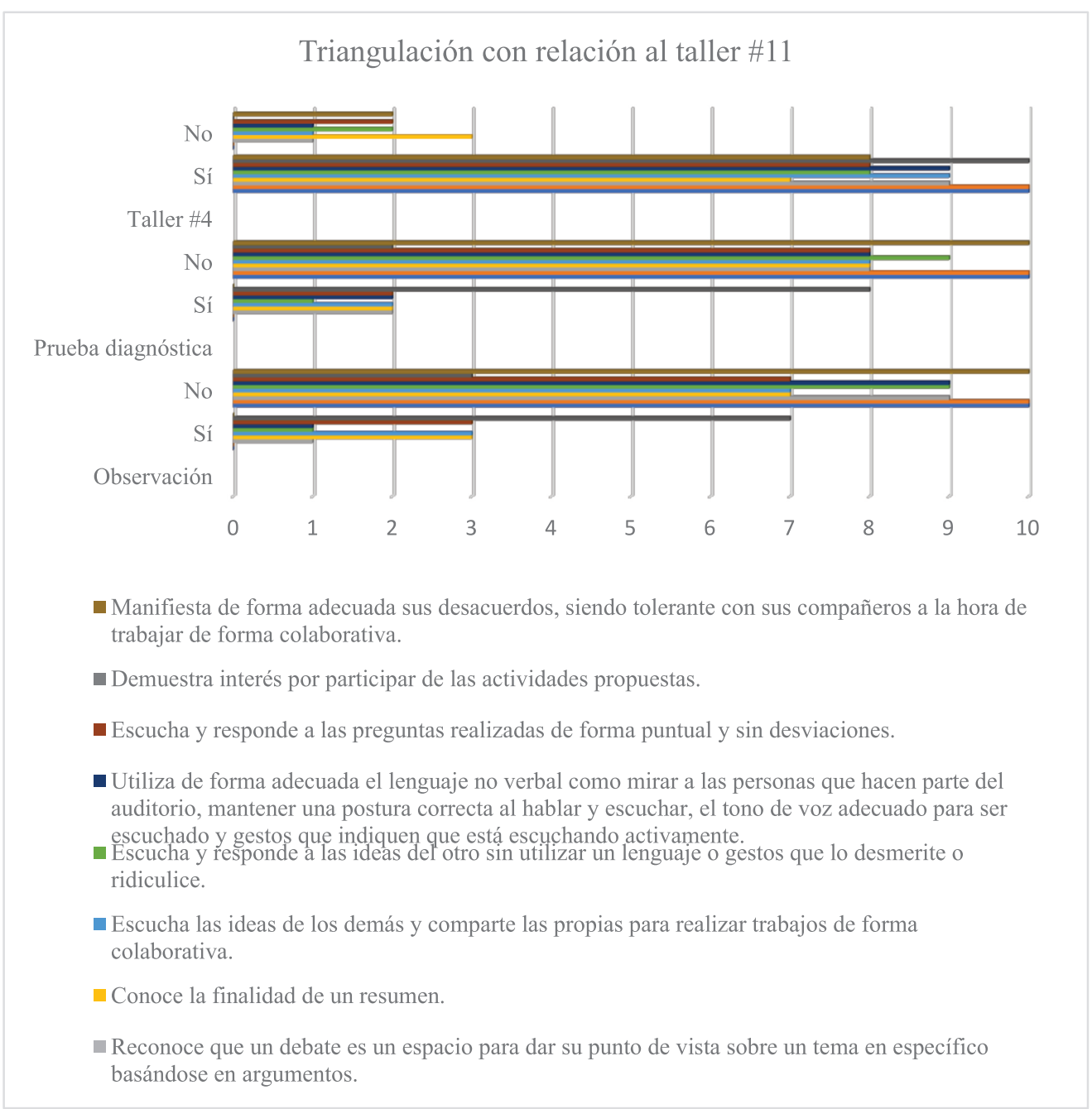

Fuente: elaboración propia.

\section{DISCUSIÓN}

A la luz de los resultados, es preciso decir que la necesidad de fortalecer la escucha activa se hace inminente puesto que, en la actualidad, gracias a las diferentes situaciones acaecidas por cuenta de la pandemia a nivel mundial originada por el Covid-19 o Coronavirus, se tuvo que recurrir de carácter imperante a la virtualidad. Lo que, a su vez, desencadenó una serie de fenómenos y de dificultades que, hasta la fecha, no han sido saciadas. De modo que la metodología del aula invertida sería de gran ayuda a la hora de facilitar los procesos educativos.

Cabe destacar que los estudiantes han dado muestras de la falta de escucha activa al interior de las aulas de clase, lo cual ha de hacer una invitación a reflexionar sobre la realidad que se ha de vivir dentro de las aulas virtuales. Por lo que se podría preguntar: ¿Cuáles son 
las estrategias implementadas por los docentes para mitigar esta situación? Así pues, partiendo de lo propuesto por Jonathan Bergmann y Aaron Sams (2007), es posible comprender las ventajas que proporciona esta metodología para la adquisición de nuevos conocimientos mientras que la habilidad de escuchar activamente es estimulada ocasionando su fortalecimiento. Gracias a que los escolares se verán comprometidos a gran escala a participar de las clases virtuales mientras que se sentirán motivados debido a que su opinión ha de tener relevancia dentro de la misma. Es decir, no solo será el maestro quien llegue a presentar el contenido de la clase, sino que los educandos llegarán con un conocimiento previo mejor desarrollado. Además, al encontrarse situados frente a los recursos que ofrece la tecnología, también se podrán ver los avances y resultados en cuanto a saber escuchar. A razón, se sienta lo expuesto por Dewey (1899, p. 30).

Hay que resaltar que la escuela es la encargada de instaurar y de desarrollar habilidades que le sirvan al ser humano para desenvolverse en los diferentes escenarios de su vida. Por eso, al llegar a la educación superior se asume que ha adquirido y desarrollado un gran número de habilidades y competencias. Pero la realidad que acontece dista de lo que se piensa. De otro lado, el ámbito laboral, está haciendo un llamado cada vez más grande con relación a la comunicación en las organizaciones, por lo que es importante tener presente que llevar a cabo tareas a nivel educativo que promulguen el fortalecimiento de la escucha activa en los estudiantes por medio de las tecnologías de la información y de la comunicación es un trabajo extenso que necesita de mucho esfuerzo y empeño para lograr que los objetivos propuestos se vean reflejados. En este punto, es preciso asir lo siguiente.

Las habilidades comunicativas deben ser comprendidas en función de la significación y la producción del sentido. Consecuente a esto, la habilidad de escuchar se relaciona con elementos pragmáticos tales como reconocer la intención del hablante, reconocer el contexto socio - cultural y la cosmovisión descle la que se habla. Así mismo, se asocia a procesos cognitivos de gran complejidad debido a que al leer se cuenta con un texto impreso utilizado como soporte de la significación, mientras que el acto de escuchar implica ir entrelazando el significado de forma rápida, por lo que se atribuyen pocas posibilidades de realizar un retroceso en el proceso de interpretación (Ministerio de Educación Nacional, 1998).

Entendido lo anterior, se muestra claramente que el estudiante de hoy debe tener una estructura amplia a nivel comunicativo que le permita enfrentarse a esas "realidades comunicativas", que no solo han de nacer en función de los contextos educativos sino, además, en los contextos laborales y personales. Es considerable pensar en que la comunicación no es un proceso simple, más bien debe verse como un proceso complejo en el que se efectúan una serie de transferencias de significados entre individuos en los que se origina un emisor y un receptor, mientras que se emplea un sistema de señales en el que se

\author{
La escuela es \\ la encargada de \\ instaurar y de \\ desarrollar \\ habilidades que \\ le sirvan al ser \\ humano para \\ desenvolverse \\ en los diferentes \\ escenarios de \\ su vida.
}


La metodología del "aula invertida" es una muy buena herramienta que conlleva al trabajo colaborativo e influye significativamente en el fortalecimiento de la escucha activa, gracias a que, de esta manera, los estudiantes son capaces de interactuar entre ellos, logrando escucharse activamente. transmiten mensajes a través de un canal o medio, que lleva a estos a relacionarse no siendo entes pasivos sino activos al interior del proceso; de ello depende el éxito de la comunicación. Bayer (2014, p. 6) a su vez, lo ve como "el proceso social más importante. Y, sin ella, el hombre se encontraría aún en el primer escaño de su desarrollo y no existirían sociedad ni cultura" (Andrade, 2009, p. 11).

Con esto, se quiere dar a entender la preponderancia que tiene el fortalecer la escucha activa desde la escuela, puesto que las realidades educativas han de transformarse cada día con miras a la globalización y a la sociedad del conocimiento, la cual busca que el hombre sea mayormente competitivo y que esté en la capacidad de adquirir nuevas habilidades que le lleven a desenvolverse con eficacia y eficiencia en el mundo laboral. Hecho que puede concebirse a partir de lo apuntado por Echeverría (1999) al decir que la escucha es una competencia necesaria para la vida. Lo que indica que, cada ser humano necesita de ella para demostrar que es capaz de enfrentarse a las diversas situaciones que se le presenten en su día a día. Además, es claro que sigue siendo un ser social que requiere de esta habilidad para relacionarse con aquellos que le rodean.

Para terminar, es prudente resaltar que si se enseña desde los primeros años escolares a escuchar activamente, se ha de reducir progresivamente la poca asertividad que se tiene al comunicar. Y se estarían formando individuos capaces de enfrentar distintos contextos comunicativos de corte académico, personal y laboral.

\section{CONCLUSIONES}

A causa de los avances presentados luego de aplicar la propuesta pedagógica "Flippeando mi oído voy afinando", se puede decir que la metodología del "aula invertida" es una muy buena herramienta que conlleva al trabajo colaborativo e influye significativamente en el fortalecimiento de la escucha activa, gracias a que, de esta manera, los estudiantes son capaces de interactuar entre ellos, logrando escucharse activamente mientras que, factores como las relaciones sociales, la atención, la comprensión y el aprendizaje, son llevados a su máxima expresión. Es decir, para poner de manifiesto sus ideas, primeramente, es necesario que escuchen al otro para así responder a lo que se ha dicho y demostrar al interlocutor que se le ha comprendido. Esto mediado por una actitud empática.

Por consiguiente, es acertado resaltar que a través del "aula invertida" los estudiantes se muestran motivados a participar de la clase, ya que, en ella, continuamente, se dan espacios en los que encuentran la oportunidad de expresar lo que han aprendido y de alimentarse de lo que sus compañeros puedan aportar, construyendo de esta forma el conocimiento que se pretende interiorizar. Se ha de dar pie a la inmersión positiva en los nuevos contextos y exigencias que se propiciarán con relación a la sociedad del conocimiento y de la globalización tanto en aras de una educación de calidad como en la adquisición de habilidades que sirvan para el buen desarrollo y funcionamiento en el mundo laboral. 


\section{REFERENCIAS}

Álvarez, E. (2001). Importancia de la escucha en la comunidad educativa [tesis de pregrado, Universidad De La Sabana] https://core.ac.uk/download/pdf/47069832.pdf

Andrade, H. (2009). Definición y alcance de la comunicación organizacional. En C. Fernández (ed), La comunicación en las organizaciones $2 a$ Ed (pp. 11-15). Trillas. http://biblioteca.udgvirtual.udg.mx:8080/jspui/ bitstream/1 23456789/3223/1/Definici\%C3\%B3n\%20y\%20alcance\%20 de\%20la\%20comunicaci\%C3\%B3n\%20organizacional.PDF

Aula Planeta. (2015, 16 de mayo). Cómo aplicar la pedagogía inversa o flipped classroom en diez pasos [infografía]. Aula Planeta. Blog. https:// www.aulaplaneta.com/2015/05/13/educacion-y-tic/como-aplicar-la-pedagogia-inversa-o-flipped-classroom-en-diez-pasos/

Bayer, C. (2005). Comunicación eficaz, una competencia para lograr el éxito organizacional [monografía, Universidad de La Sabana] https://intellectum.unisabana.edu.co/bitstream/handle/10818/4624/130814.pdf

Berenguer, C. (2016). Acerca de la utilidad del aula invertida o flipped classroom. En M. Tortosa, S. Grau y J. Álvarez (Ed.), XIV Jornadas de redes de investigación en docencia universitaria. Investigación, innovación y enseñanza universitaria: enfoques pluridisciplinares. (pp. 1466-1480). Alicante, España: Universitat d'Alacant. ISBN: 978-84-608-7976-3.

Bergmann, J., Aaron S. (2016). Dale la Vuelta a tu Clase. Biblioteca Innovación Educativa SM.

Beuchat, C. (1989). Escuchar el punto de partida. En lectura y vida. Lectura y vida. http://www.lecturayvida.fahce.unlp.edu.ar/numeros/a10n3/10_03_ Beuchat.pdf.

Ceballos, H., Isaza. G. y Ramírez, D. (2014). Habla y escucha: Habilidades que se fortalecen a través del uso de las tecnologías de la información y de la comunicación (TIC) en estudiantes de grado octavo. Plumilla Educativa, Volumen 15 Número 1(2015) https://doi.org/10.30554/plumillaedu.15.844.2015

Dewey, J. (1899). La escuela y la sociedad.

Echeverría, R. (1994). Ontología del lenguaje. JC Sáez Editor.

Echeverría, R. (2002). Ontología del lenguaje; el escuchar: el lado oculto del lenguaje. JC Sáez Editor.

Echeverría, R. (2006a). Escrito sobre aprendizaje: Recopilación. Ediciones Granica SA.

Echeverría, R. (2006b). Actos del lenguaje volumen I: La escucha. JC Sáez Editor. 
Elizondo, M. (1999). Asertividad y escucha activa en el ámbito académico. Trillas.

Falcones, E. y Yoza, R. (2018). Influencias metodológicas del desarrollo del pensamiento en el nivel de razonamiento lógico. propuesta: diseño de una guía didáctica con enfoque aula invertida [tesis de pregrado, Universidad de Guayaquil] http://repositorio.ug.edu.ec/bitstream/redug/26111/1/BFILO-PFM-18P01.pdf

Fernández., R. V. (2013). Habilidades personales para la convivencia familiar. España: Escuela de bienestar.

García, J. (2009, 2 de enero). Comunicación: La escucha activa. psicoterapeutas.com Blog. http://www.psicoterapeutas.com/terapia_de_pareja/escucha_activa.html.

Herrera, S. (2003). El Aprendizaje Colaborativo como una Herramienta de la Actividad Tutoría [monografía, Universidad Autónoma de Campeche] https://docplayer.es/15782125-El-aprendizaje-colaborativo-como-una-herramienta-de-la-actividad-tutorial.html

Johnson, D., Johnson, R. (1991). Cooperative learning lesson structutres. Edina, M.N: Interaction Books.

Lomas, C. (2002). El aprendizaje de la comunicación en las aulas. Paidós.

López, J. (2006). Las competencias básicas del currículo en la LOE. [sesión de conferencia] V Congreso Internacional "Educación y sociedad”. https:// iessecundaria.files.wordpress.com/2008/10/las-competencias-basicas-del-curriculo-en-la-loe-articulo-de-juan-lopez.pdf

MEN, (1998). Lineamientos curriculares de lengua castellana. https://www. mineducacion.gov.co/1621/articles-89869_archivo_pdf8.pdf

Ortiz, R. (2007). Aprender a escuchar, cómo desarrollar la capacidad de escucha activa. Lulu. http://www.aprenderaescuchar.es/images/AprenderaEscuchar_Preview.pdf

Prensky, M. (2010). Nativos e Inmigrantes Digitales.

Ramírez, A., Salinas, A., Sarmiento, B., Ayala, E., Pachón, J., Serrano, K., Moreno, L., Parra, L., García, L. (2009) La indiferencia y el descuido de la escucha en el aula [tesis de pregrado, Corporación Universitaria Minuto de Dios] https://repository.uniminuto.edu/bitstream/handle/10656/379/ THUM_RealRusbert_09.pdf?sequence $=3$ \&isAllowed $=\mathrm{y}$

Walvoord, B. y Johnson Anderson, V. (1998). Effective grading: A tool for learning and assessment. Jossey-Bass

White, D. y Le Cornu, A. (2011, 5 de septiembre). Visitantes y Residentes: Una nueva tipología para la participación en línea. First Monday, 16(9-5). 